\title{
Agglomeration Economies: Population, Density, and Network Effects
}

Thomas J. White, (Email: twhite@assumption.edu), Assumption College

\begin{abstract}
This paper builds on the optimal city size literature by examining factors that influence location benefits and costs. Total population, population density, employment type, and networking are evaluated using ordinary least squares. Results indicate that population density may play a more significant role in predicting average location benefits and average location costs than population.
\end{abstract}

\section{Introduction}

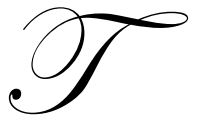

here exists a substantial literature discussing the optimal or efficient city size. Mills (1967) and later Henderson (1974) described how increases in a city's population allow for certain economies of scale in production to be realized. These agglomeration economies as they have come to be known are offset by increased transportation costs that occur as a city spreads out spatially and as roads become more congested. Given such benefits and costs, Henderson (1974) defined the concept of optimum city size as the population that maximizes net benefits of agglomeration (i.e. marginal benefits from agglomeration economies are just offset by marginal transportation cost). Estimating such an optimum has proven to be difficult however, as it has become apparent that agglomeration benefits and costs are influenced by more than just city size. Network effects such as knowledge spillovers, innovation, and concentration of human capital have been described as important sources of agglomeration economies (Rauch, 1993; Jaffe, et. al. 1993). These sources have been shown to be of different magnitudes depending on city size, as well as the type of production that occurs in the city (Henderson, 1985; Capello \& Camagni, 2000).

Capello and Camagni (2000) presented an alternative model to examine how city size and other factors influence agglomeration economies. The model incorporated city size, network effects, and type of production to explain agglomeration benefits and costs. It is the interaction of these variables that is of particular interest. For example, Capello and Camagni argue that a city that engages in "high-order" economic functions, (i.e. production that requires high levels of specialization) will tend to have a greater efficient city size than a city with "low-order" production. This is consistent with the literature on central place theory that extends back to Losch (1954) and Christaller (1966) which explains why cities are not all converging to a single efficient or optimal population.

In addition to production type, Capello and Camagni (2000) included network effects in their model in order to explain how some relatively small cities may attain high-order economic functions. Capello and Camagni (2000) apply the network city model to explain this phenomenon. In the network city model, a city that is highly networked both within and between cities will be able to serve higher order functions than a city of similar size that is not as highly networked.

The agglomeration economies that provide the economic explanation for the existence of cities focus on the net benefits that are derived from additional city population. Ciccone and Hall (1996) have argued that agglomeration economies can be better explained by using population density rather than total population. They develop a model that explains how more densely populated areas will tend to have higher levels of productivity than similar though less dense areas. The additional productivity arises from three possible effects. First, greater density in the production of intermediate goods may reduce the transportation cost of transporting those goods. Second, 
greater density may lead to higher positive externalities of production, where such externalities exist. Finally, greater density will allow for a higher degree of specialization (Ciccone and Hall, 1996).

This paper makes use of the empirical model of Capello and Camagni to examine how high-order economic functions, network affects and density influence location benefits and costs. The next section will present the theoretical underpinnings of the model. Section three will discuss the empirical estimation and section four will discuss further research to be conducted.

\section{Empirical Model}

Capello and Camagni (2000) estimate an average location benefit function and an average location cost function using a translog functional form. The average location benefit function is as follows:

$$
\begin{aligned}
\ln B E N= & \ln \eta+\alpha_{1} \ln P O P+\alpha_{2} \ln F U N+\alpha_{3} \ln N E T \\
& +\beta_{1} \frac{1}{2}(\ln P O P)^{2}+\beta_{2} \frac{1}{2}(\ln F U N)^{2}+\beta_{3} \frac{1}{2}(\ln N E T)^{2} \\
& +\delta_{1} \ln P O P \ln F U N+\delta_{2} \ln P O P \ln N E T+\delta_{3} \ln F U N \ln N E T
\end{aligned}
$$

where, BEN represents the average location benefits from agglomeration economies, POP represents urban population, FUN the degree of high-order economic functions in the city, and NET the degree of network interaction. The squared terms on the right-hand side are included in order to estimate the likely non-linear relationship between the explanatory variables and location benefits. In addition, the interaction terms will allow for the estimation of the influence that a change in one factor has on the degree to which another factor affects location benefits.

Obtaining estimates of the elasticity of benefits with respect to population, economic function, or networking is straightforward when using the translog form since elasticity will be the derivative of (1) with respect to the variable of interest. For example,

$$
\varepsilon_{P O P}=\frac{\partial \ln B E N}{\partial \ln P O P}=\alpha_{1}+\beta_{1} \ln P O P+\delta_{1} \ln F U N+\delta_{2} \ln N E T
$$

This shows explicitly that a change in either FUN or NET will affect the sensitivity of location benefits relative to population. In this case, it is predicted that $\beta_{1}$ will be negative, since a percentage increase in population will provide a smaller percentage increase in benefits the larger the city. The coefficient $\delta_{1}$ is expected to be positive, as a city with greater levels of high-order employment will achieve greater benefits from additional population than cities with lower levels of high-order employment. Coefficient $\delta_{2}$ is also expected to be positive, since greater networking will increase the amount of benefits from additional population.

The average location cost function is of a similar form to equation (1):

$$
\begin{aligned}
\ln C O S T & =\ln \eta+\alpha_{1} \ln P O P+\alpha_{2} \ln F U N+\alpha_{3} \ln N E T \\
& +\beta_{1} \frac{1}{2}(\ln P O P)^{2}+\beta_{2} \frac{1}{2}(\ln F U N)^{2}+\beta_{3} \frac{1}{2}(\ln N E T)^{2} \\
& +\delta_{1} \ln P O P \ln F U N+\delta_{2} \ln P O P \ln N E T+\delta_{3} \ln F U N \ln N E T
\end{aligned}
$$

where, COST represents the average location costs. As in the benefits case, the equation for the elasticity of location cost with respect to any of the explanatory variable can be easily determined. 
As discussed in the introduction, Ciccone and Hall (1996) have argued that population density is more important than total population in determining the benefits derived from cities. The purpose of this paper is to examine whether density provides a better explanation of benefits and costs when using the framework of Capello and Camagni (2000). Equations (1) and (3) are therefore modified to include density rather than population. These equations are:

$$
\begin{aligned}
\ln B E N= & \ln \eta+\alpha_{1} \ln D E N+\alpha_{2} \ln F U N+\alpha_{3} \ln N E T \\
& +\beta_{1} \frac{1}{2}(\ln D E N)^{2}+\beta_{2} \frac{1}{2}(\ln F U N)^{2}+\beta_{3} \frac{1}{2}(\ln N E T)^{2} \\
& +\delta_{1} \ln D E N \ln F U N+\delta_{2} \ln D E N \ln N E T+\delta_{3} \ln F U N \ln N E T \\
\ln C O S T & =\ln \eta+\alpha_{1} \ln D E N+\alpha_{2} \ln F U N+\alpha_{3} \ln N E T \\
& +\beta_{1} \frac{1}{2}(\ln D E N)^{2}+\beta_{2} \frac{1}{2}(\ln F U N)^{2}+\beta_{3} \frac{1}{2}(\ln N E T)^{2} \\
& +\delta_{1} \ln D E N \ln F U N+\delta_{2} \ln D E N \ln N E T+\delta_{3} \ln F U N \ln N E T
\end{aligned}
$$

where DEN represents the average density of the urban population measured as population per square mile.

\section{Estimation}

In order to obtain coefficient estimates for equations (1), (3), (4), and (5) data were collected for 131 U.S. cities. Data sources can be found in the appendix.

The variables BEN and COST were derived from a variety of indicators of urban benefits and costs. As Capello and Camagni (2000) explain, cities generate both positive and negative externalities. Positive externalities may arise from more efficient use of natural resources such as water or petroleum, greater economic vitality from specialization in production, or greater access to natural areas. Negative externalities may result from the disposal of waste products resulting from production or consumption, increases in crime, and other social problems that may result from growth in income inequality. The indicators that measure positive externalities were aggregated into a single value by summing the indicators when expressed as a proportion of the maximum value of that indicator. The resulting sum was used as the BEN variable in estimating equation (1) and (4). The indicators for negative externalities were aggregated in a similar fashion to obtain the COST variable of equations (3) and (5). See the appendix for a list of indicators used in the calculation of BEN and COST.

The data used for the explanatory variables also deserve some clarification. POP is the total population of the urban area as reported by the 2000 U.S. Census. DEN is population per square mile. FUN is the variable for economic function of the city. This variable was expressed as the percentage of high-order employment in the city, where high-order employment was defined as employment in any of the following industries: information, finance, insurance, real estate, professional scientific, management, administration, education, health care, arts and entertainment. The NET variable was the proportion of homes that have internet access.

Coefficient estimates for equations (1), (3), (4), and (5) were obtained using ordinary least squares. Table 1 shows the estimated coefficients and t-statistics.

For equation (1), only two coefficient estimates were significantly different from zero, both associated with the high-order economic function variables. The coefficient estimate of $\square_{2}$ has the predicted positive sign, indicating that as the amount of high-order employment increases in a city the average location benefits increase at an increasing rate. This result is consistent with what Capello and Camagni (2000) found for 58 Italian cities. The coefficient estimates for the population and network variables, as well as all the interaction terms were insignificant for equation (1). 
TABLE 1

Coefficient estimates using ordinary least squares.

\begin{tabular}{|c|c|c|c|c|}
\hline Coefficient & Equation (1) & Equation (3) & Equation (4) & Equation (5) \\
\hline$\eta$ & 5.789 & -6.885 & $12.175^{* *}$ & -9.698 \\
& $(0.835)$ & $(-0.548)$ & $(2.554)$ & $(-1.070)$ \\
\hline$\alpha_{\square}$ & 0.629 & -0.510 & $-8.069 \times 10^{-2}$ & -1.061 \\
& $(1.041)$ & $(-0.466)$ & $(-0.159)$ & $(-1.099)$ \\
\hline$\alpha_{2}$ & $-6.613^{* * *}$ & 5.393 & $-7.997^{* * *}$ & $8.366^{*}$ \\
& $(-2.824)$ & $(1.363)$ & $(-3.559)$ & $(1.974)$ \\
\hline$\alpha_{3}$ & 1.640 & -0.071 & $2.561^{*}$ & -1.629 \\
& $(1.033)$ & $(-0.025)$ & $(1.684)$ & $(-0.564)$ \\
\hline$\beta_{\square}$ & $-7.718 \times 10^{-4}$ & 0.067 & $2.301 \times 10^{-2}$ & $7.367 \times 10^{-2 *}$ \\
& $(-0.031)$ & $(1.466)$ & $(1.124)$ & $(1.893)$ \\
\hline$\beta_{\square}$ & $2.527 * * *$ & -1.478 & $2.585^{* * *}$ & $-2.772^{*}$ \\
& $(3.540)$ & $(-1.142)$ & $(3.321)$ & $(-1.822)$ \\
\hline$\beta_{\square}$ & -0.377 & -0.015 & $-0.388^{*}$ & -0.452 \\
& $(-1.633)$ & $(-0.035)$ & $(-1.730)$ & $-1.061)$ \\
\hline$\delta_{\square}$ & -0.214 & $8.140 \times 10^{-3}$ & -0.111 & 0.130 \\
& $(-1.643)$ & $(0.035)$ & $(-0.841)$ & $(0.516)$ \\
\hline$\delta_{2}$ & $6.300 \times 10^{-4}$ & -0.088 & $0.102^{* *}$ & $4.402 \times 10^{-2}$ \\
& $(0.926)$ & $(-0.713)$ & $(1.931)$ & $(0.438)$ \\
\hline$\delta_{3}$ & -0.213 & 0.199 & -0.372 & 0.629 \\
& $(-0.563)$ & $(0.290)$ & $(-0.967)$ & $0.860)$ \\
\hline Adjusted $\mathrm{R}^{2}$ & 0.352 & 0.381 & 0.351 & 0.319 \\
\hline
\end{tabular}

* Significant at $\alpha=.10$

** Significant at $\alpha=.05$

*** Significant at $\alpha=.01$

Coefficients for the average location benefit function that included density rather than population (equation (4)), were also estimated. As in equation (1), the coefficients for the high-order function variables were significant and of the predicted sign. In addition, the coefficients on the networking variables $\left(\alpha_{3} \square \square \beta_{3}\right)$ were significant at $\alpha=$ 0.10 . However, the coefficient estimate for $\beta_{3}$ was less than zero implying that increases in networking increase benefits at a decreasing rate, which contradicts the predicted relationship.

Also significant in equation (4) was the coefficient on the interaction between density and the level of networking $\left(\delta_{2}\right)$. This suggests that increases in networking will create more benefit in cities that are denser than in less dense cities. This is consistent with expectations.

The two versions of the average location cost functions were also estimated using ordinary least squares (equations (3) and (5)). Equation (3) did not have any significant coefficient estimates, while equation (5) had three coefficient estimates that were significant at the $10 \%$ level. The positive and significant sign for $\beta_{1}$ implies that increases in density increase average location costs at an increasing rate, which is consistent with expectations. The estimate of $\beta_{2}$ was less than zero, implying an increase in high-order functions increase costs at a decreasing rate, again consistent with expectations.

\section{Conclusions}

Overall, the empirical results provide some evidence that density may be more useful than population as a predictor of average location benefits and costs. The density of a city does seem to influence the amount of benefits that arise from increases in networking. In addition, there appears to be a significant relationship between density and average location costs, which does not seem to be the case with population. 


\section{Appendix}

\section{Data Sources}

Components of BEN:

Non-transportation energy use per capita - Energy Information Administration, http://www.eiq.doe.gov

Transportation energy use per capita- Energy Information Administration, http://www.eiq.doe.gov

Water use per capita - U.S. Geological Survey, http://water.usgs.gov/watuse

Percentage of college graduates - U.S. Census Bureau, Supplementary Survey 2000 http://www.census.gov

Banks per capita - State and Metropolitan Area Data Book, 1997-1998

Movie screens per capita - Places Rated Almanac, 2000

Hospitals beds per capita - State and Metropolitan Area Data Book, 1997-1998

Green area per capita - Places Rated Almanac, 2000

Income per capita - U.S. Census Bureau, 2000 Census

Median rent - U.S. Census Bureau, 2000 Census

Components of COST:

Ozone concentration - National Air Quality and Emissions Trends Report, 2000

Carbon dioxide emissions per capita - National Air Quality and Emissions Trends Report, 2000

Unemployment rate - Bureau of Labor Statistics, www.bls.gov

Murder rate - Places Rated Almanac, 2000

Violent crime rate - Places Rated Almanac, 2000

Motor vehicles per capita - U.S. Census Bureau, 2000 Census

POP: 2000 Population - U.S. Census Bureau, 2000 Census http://www.census.gov

DEN: Population/Land Area Land Area - State and Metropolitan Area Data Book, 1997-1998

FUN: Percentage of high-order employment Employment by industry - U.S. Census Bureau, Statistics of U.S. Businesses http://www.census.gov

NET: Percentage of homes with internet access Internet Usage - Bureau of Labor Statistics http://www.bls.census.gov/cps/computer/sdata.htm

\section{References}

1. Capello, R. and Camagni R. (2000) Beyond Optimal City Size: An Evaluation of Alternative Urban Growth Patterns, Urban Studies, 37, pp. 1479-1496.

2. Christaller, W. (1966) Central Places in Southern Germany, trans. C.W. Baskin. Englewood, NJ: Prentice Hall.

3. Ciccone, A. and Hall, R.E. (1996) Productivity and the Density of Economic Activity, American Economic Review, 86, pp. 54-70.

4. Henderson, J.V. (1974) The Sizes and Types of Cities, American Economic Review, 64, pp. 640-656.

5. Henderson, J.V. (1985) Economic Theory and the Cities, Orlando, FL: Academic Press 
6. Jaffe, A.B., Trajtenberg, M., and Henderson, R., (1993) Geographic localization of knowledge spillovers as evidenced by patent citations, Quarterly Journal of Economics, 108, pp. 577- 598.

7. Losch, A. (1954) The Economics of Location, New Haven CT: Yale University Press.

8. Mills, E.S. (1967) An Aggregative Model of Resource Allocation in a Metropolitan Area, American Economic Review, Papers and Proceedings, 57, pp. 197-210.

9. Rauch, J.E. (1993) Productivity Gains from Geographic Concentration of Human Capital: Evidence from the Cities, Journal of Urban Economics, 34, pp. 380-400.

10. Savageau, D. and D'Agostino, R. (2000) Places Rate Almanac, Foster City, CA: IDG Books.

11. U.S. Census Bureau (1998) State and Metropolitan Area Data Book, 1997-1998, $5^{\text {th }}$ Edition, Washington DC.

12. U.S. Census Bureau (2001) 1997 Economic Census, Retrieved from http://www.census.gov/ epcd/www/econ97.html

13. U.S. Census Bureau (2001) United States Census 2000. Retrieved fromhttp://www.census.gov/ main/www/cen2000.html

14. U.S. Geological Survey (1995) Water Use in the United States. Retrieved from http://water.usgs.gov/watuse/

15. U.S. Department of Energy (2000) Energy Consumption Estimates by Source and End-Use Sector. Retrieved from http://www.eia.doe.gov/emeu/states/sep_sum/html/pdf/sum_use_all.pdf 